\title{
REGIONAL STRUCTURAL ECONOMIC DISPARITIES IN BULGARIA
}

\author{
Iv. Stoycheva
}

\author{
Department of Economics, Faculty of Economics, Trakia University, Stara Zagora, Bulgaria
}

\begin{abstract}
The article presents a comparative assessment of the differences in the economic structures of the different regions. The aim is to measure the difference that exists between the regions by tracking changes in the structure over a period covering development before, during and after the economic crisis. An answer to the question is whether the economic structure of a region is adequate to existing economic circumstances. On the basis of a structured approach in selected sectors and through a system of indicators the changes in the structure were examined; and through correlation coefficients the strength and direction of dependence of selected regional indicators established. The analysis showed that the different economic advantages available to individual regions lead to different economic potential, which in turn adds to the contrast between the regions. The dynamics, nature and depth of territorial inequalities predetermine structures that meet the comparative advantages of the regions and this, in turn, is the basis for a differentiated structural economic policy
\end{abstract}

Key words: Regional differences, structural changes, labor productivity

\section{INTRODUCTION}

As a rule, lagging regions have a higher share of the agrarian sector, and it is characterized by lower labor productivity. Changes related to reducing the share of the agrarian sector at the expense of the industrial sector as well as services, lead to an increase in the relative share of activities with higher labor productivity and hence to greater efficiency of the economy and economic growth.

According to Kuznets (1) "structural changes . . . are necessary, without which modern economic growth is impossible ". For Pasinetti (2), economic growth is linked to permanent structural transformations and changes.

Economic development implies changes related to the relative participation of individual sectors or parts thereof, and this, in turn, results in the construction of different economic structures, depending on the stage of development of the region. The divergence in the development of the sectors predetermines the different development potential of the regions and, having in mind the economic circumstances of a given region, there is unevenness in the structure of production and employment.

\footnotetext{
*Correspondence to: Ivanka Stoycheva, Department of Economics, Faculty of Economics, Trakia University,Stara Zagora, Bulgaria, e-mail: vania_jekova@abv.bg,phone: +35942699430
}

The article discusses structural changes as a factor determining the economic development of the regions in the Republic of Bulgaria at the level of statistical regions (NUTS2 - 6 statistical regions) and their constituent areas (NUTS3 - 28 districts), aiming at a comparative assessment of the degree of economic development of the individual regions by structural analysis in selected sectors and by a system of indicators to measure the difference that exists between the regions.

When analyzing structural changes and differences, the aggregation of three main sectors, namely Agrarian, Industry and Services, and the years selected (2000, 2007 and 2015) allow changes over a long period of time to be tracked. These are the main sectors that reflect in the most aggregated form the structural changes and differences.

\section{MATERIAL AND METHODS}

The comparative analysis of the statistical regions and their constituent areas is made using relative dimensional structures. The relative share of selected sectors in GVA (Gross value added) and the share of employed in these same sectors is established. The calculated relative magnitudes make it possible to compare the changes in the structure of the studied sectors and to assess the differences in the structure by main sectors, respectively, the differences in labor productivity of 
the region as well as the district having in mind the changes in the relative share of a sector. The relative labor productivity index for the relevant district has been calculated as the ratio between the share of a sector in GVA and the share of employees in the same sector. The differences in the structure of the regional indicators, both by districts and by years, their intensity and their relationship with macroeconomic indicators are of interest.

The Pearson linear correlation coefficient was used to determine the dependence of the selected regional indicators. It provides an assessment of the degree of dependence between the share of selected sectors in the GVA and the share of employed in these sectors and the GDP per person indicator.

These relationships were also evaluated by a spiraling correlation coefficient, and in its calculation, the individual observations of the two variables were ranked and an assessment of the closeness of the relationship based on their ranks was made.

To draw conclusions, on the significance of the linear correlation coefficient and that of the Spirman ranging correlation the observed level of significance $\alpha \leq 0,05$ is used.

\section{RESULTS AND DISCUSSIONS}

The structure of GVA by economic sectors and the structure of the employed in the same sectors in 2000, 2007 and 2015 was calculated, as well as the relative productivity of labor by individual sectors as a ratio between the share of the respective sector in GVA and the share of those employed in the same sector (Table 1). At a total average labor productivity for the country, $100 \%$ of the agrarian sector has a relative labor productivity of $57.8 \%$ in 2000, 27.9\% in 2007 and in 2015 27.1\%. This decline in total labor productivity in our country is unfavorable (for the agrarian sector) and it is mainly due to the drastic reduction of the participation of this sector in GVA in 2007 and 2015 compared to 2000.

In 2015, compared with 2007, there were no significant changes in the structure of employed, GVA and relative labor productivity, but there were significant differences in the structure of observed indicators between these two years and 2000 .

For the three years, the share of the employed and the share of GVA in the agrarian sector is highest in the districts of Silistra, Razgrad, Dobrich, Kardzhali, Yambol, and is the lowest in the districts of Sofia-city, Varna, Pernik, Gabrovo, Stara Zagora . Dynamically, there is a change in these two indicators in the direction of an increase in the share of employed and a decrease in the share of GVA in the regions of Vidin, Vratsa, Montana and
Kardzhali, Yambol. Overall, the share of GVA in the Agrarian sector remains the highest for the three years in the Northwest region, and this stems from the specificity of the region with the highest share of arable land per capita.

The comparative analysis of the Industry sector allows identifying areas with high employment. These are Gabrovo, Stara Zagora, Kyustendil, Blagoevgrad, Pernik, Lovech and Russe. The share of GVA in Industry during the observed period is the highest in the Southeastern region, which identifies it as an area with a better prospect of development due to relatively favorable demographic and economic indicators.

In the services sector, the share of employed and that of GVA in the districts of Varna, Burgas, Sofia-city, Plovdiv is the largest. This may be linked to the meanings of the relative labor productivity indicator, which for the three years is the highest in these cities. Therefore, it is precisely in these urbanized centers that the decline in the share of Industry is an increase in the share of services. The services sector has the greatest potential for development where the relative productivity of labor is significantly higher than in other sectors and this is a prerequisite for the favorable economic development of this sector in the mentioned areas and the related municipalities.

An important aspect of the study is to assess how changes in the structure of employees and the share of GVA by major sectors affect the economic growth of the region. The correlation coefficient calculated for 28 districts of the Republic of Bulgaria between the share of the agrarian sector in GVA and GDP per person is minus 0.757 for 2000 . The importance of this coefficient in 2007 is minus 0.661 and for 2015 it is minus 0.638. This determines the presence of inverse proportional dependence and it can be concluded that the high share of agriculture in GVA is indicative of lower GDP per capita or lower development potential.

The structure of the employed in the monitored sectors is decisive for the level of GDP per capita, as well as for the formation of disparities between the regions under this indicator. The statistical analysis of the relationship between the relative share of the employed in the agrarian sector and GDP per person shows that there is a negative correlation over the three years (2000 minus 0.516, 2007 minus 0.657, and 2015 minus 0.650). The strength and direction of dependence between the share of employed in agriculture and per person GDP is an indicator of the level of development of a region, with the higher share of employees in the agrarian sector leading to a less favorable level of GDP per person. Therefore, the high participation of the employed in this sector is a determining factor for the level and direction of the change in the labor productivity, and hence the development of a country or region. 


\begin{tabular}{|c|c|c|c|c|c|c|c|c|c|c|c|c|c|c|c|c|c|c|c|c|c|c|c|c|c|c|c|}
\hline \multirow[t]{2}{*}{ Regi } & \multicolumn{3}{|c|}{$\begin{array}{l}\text { GVA by } \\
\text { economic } \\
\text { sectors \%, } \\
2000\end{array}$} & \multicolumn{3}{|c|}{$\begin{array}{l}\text { GVA by } \\
\text { economic } \\
\text { sectors \%, } \\
2007\end{array}$} & \multicolumn{3}{|c|}{$\begin{array}{l}\text { GVA by } \\
\text { economic } \\
\text { sectors, \%, } \\
2015\end{array}$} & \multicolumn{3}{|c|}{$\begin{array}{l}\text { Employed by } \\
\text { economic } \\
\text { sectors ,\%, } 2000\end{array}$} & \multicolumn{3}{|c|}{$\begin{array}{c}\text { Employed by } \\
\text { economic } \\
\text { sectors , \%, } \\
2007\end{array}$} & \multicolumn{3}{|c|}{$\begin{array}{c}\text { Employed by } \\
\text { economic } \\
\text { sectors ,\%, } \\
2015\end{array}$} & \multicolumn{3}{|c|}{$\begin{array}{l}\text { Relative } \\
\text { productivity of } \\
\text { labor , \%, } \\
2000\end{array}$} & \multicolumn{3}{|c|}{$\begin{array}{c}\text { Relative } \\
\text { productivity of } \\
\text { labor, \%, } \\
2007\end{array}$} & \multicolumn{3}{|c|}{$\begin{array}{c}\text { Relative } \\
\text { productivity of } \\
\text { labor, } \%, 2 \\
015\end{array}$} \\
\hline & 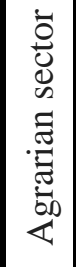 & 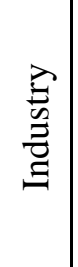 & 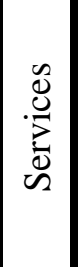 & 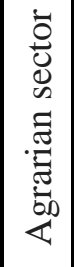 & 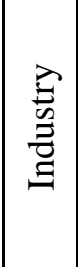 & 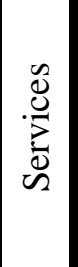 & 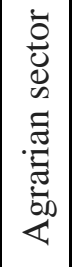 & $\begin{array}{l}\stackrel{\overparen{E}}{\mathscr{E}} \\
\stackrel{\Xi}{\Xi} \\
\Xi\end{array}$ & 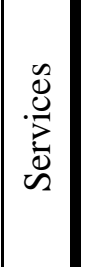 & 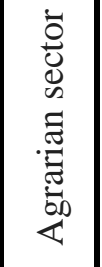 & 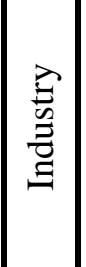 & 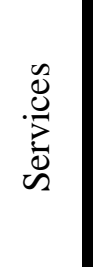 & 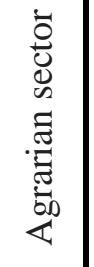 & 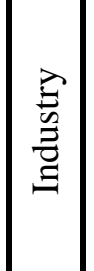 & $\cdot \frac{0}{0}$ & 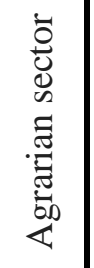 & $\begin{array}{l}\overparen{Z} \\
\text { 全 } \\
\Xi \\
\Xi\end{array}$ & 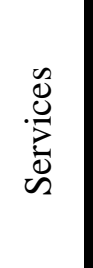 & 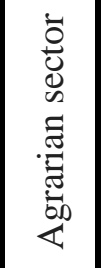 & $\begin{array}{l}\vec{E} \\
\stackrel{0}{0} \\
\vec{\Xi} \\
\Xi\end{array}$ & 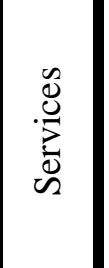 & 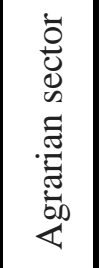 & $\begin{array}{l}\vec{E} \\
\overrightarrow{0} \\
\vec{\Xi} \\
\underline{\Xi}\end{array}$ & 总 & 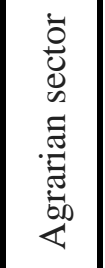 & $\begin{array}{l}\vec{E} \\
\overrightarrow{0} \\
\vec{\Xi} \\
\underline{\Xi}\end{array}$ & 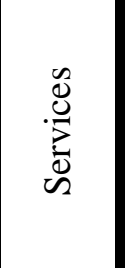 \\
\hline & 1 & 2 & 3 & 4 & 5 & 6 & 7 & 8 & 9 & 10 & 11 & 12 & 13 & 14 & 15 & 16 & 17 & 18 & 19 & 20 & 21 & 22 & 23 & 24 & 25 & 26 & 27 \\
\hline Bulgaria & 13,9 & 24,5 & 61,5 & 5,4 & 22,7 & 71,8 & 5,3 & 22,7 & 72,0 & 24,1 & 23,6 & 52,3 & 19,4 & 22,4 & 58,2 & 19,4 & $\mid 19,9$ & 60,7 & 57,8 & 103,9 & 117,7 & 27,9 & $\mid 101,4$ & 123,5 & 27,1 & $|114,5|$ & 118,5 \\
\hline Northwest & 19,3 & 30,0 & 50,6 & 10,8 & 29,2 & 60,0 & 12,6 & 30,6 & 56,8 & 29,4 & 23,9 & 46,7 & 26,4 & 25,5 & 48,0 & 29,2 & 23,1 & 47,7 & 84,5 & 107,1 & 103,1 & 40,8 & 114,4 & 124,9 & 43,1 & 132,6 & 119,1 \\
\hline Vidin & 22,6 & 8,8 & 68,6 & 16,5 & 13,9 & 69,5 & 17,9 & 13,8 & 68,3 & 22,9 & 28,0 & 49,1 & 22,6 & 19,2 & 58,2 & 32,2 & 15,7 & 52,1 & 106,9 & 42,1 & 118,5 & 73,2 & 72,5 & 119,5 & 55,6 & 87,7 & 131,1 \\
\hline Vratsa & 13,9 & 51,2 & 34,9 & 9,2 & 39,5 & 51,3 & 10,4 & 44,5 & 45,1 & 21,1 & 21,0 & 57,8 & 20,8 & 26,5 & 52,7 & 30,2 & 21,1 & 48,7 & 77,2 & 164,2 & 68,7 & 44,3 & 149,2 & 97,3 & 34,5 & 211,1 & 92,6 \\
\hline Lovech & 17,2 & 28,8 & 54,0 & 8,4 & 31,7 & 59,9 & 10,9 & 34,0 & 55,1 & 18,1 & 31,2 & 50,8 & 23,5 & 30,4 & 46,1 & 26,8 & 31,2 & 42,0 & 59,5 & \begin{tabular}{|l|}
94,6 \\
\end{tabular} & 132,7 & 35,8 & 104,2 & 129,9 & 40,5 & 109,2 & 131,1 \\
\hline Montana & 25,7 & 14,0 & 60,3 & 14,9 & 22,2 & 62,9 & 17,4 & 22,6 & 60,0 & 28,9 & 30,5 & 40,7 & 21,3 & 28,6 & 50,1 & 30,7 & 22,6 & 46,7 & 131,3 & 49,4 & 115,7 & 70,1 & 77,5 & 125,6 & 56,8 & 99,7 & 128,5 \\
\hline Pleven & 22,7 & 21,1 & 56,2 & 9,5 & 28,0 & 62,5 & 11,4 & 24,8 & 63,8 & 19,6 & 28,3 & 52,1 & 34,2 & 22,9 & 42,9 & 28,2 & 22,4 & 49,4 & 93,6 & 79,3 & 114,3 & 27,8 & 121,9 & 145,9 & 40,5 & 110,6 & 129,1 \\
\hline North central & 19,4 & 25,8 & 54,8 & 9,2 & 27,7 & 63,2 & 10,4 & 31,0 & 58,7 & 24,3 & 26,6 & 49,2 & 26,0 & 27,1 & 46,9 & 27,0 & 25,8 & 47,3 & 75,7 & 92,0 & 118,2 & 35,3 & 102,1 & 134,6 & 38,4 & 120,2 & 124,1 \\
\hline Veliko_Tarnovo & 16,5 & 25,1 & 58,4 & 6,8 & 22,5 & 70,7 & 8,4 & 24,3 & 67,4 & 25,6 & 28,0 & 46,4 & 25,9 & 24,9 & 49,2 & 25,9 & 22,6 & 51,4 & 60,7 & 96,7 & 124,6 & 26,4 & \begin{tabular}{|l|}
90,4 \\
\end{tabular} & 143,6 & 32,2 & 107,3 & 131,0 \\
\hline Gabrovo & 12,2 & 37,3 & 50,6 & 4,0 & 43,4 & 52,6 & 4,6 & 46,8 & 48,6 & 27,2 & 26,0 & 46,8 & 14,7 & 40,9 & 44,4 & 11,4 & 42,0 & 46,6 & 89,7 & 88,5 & 114,1 & 26,9 & 106,2 & 118,6 & 40,3 & 111,5 & 104,2 \\
\hline Razgrad & 28,0 & 22,4 & 49,7 & 16,8 & 24,6 & 58,5 & 16,7 & 33,5 & 49,8 & 13,5 & 42,1 & 44,3 & 32,2 & 19,9 & 47,9 & 38,3 & 18,4 & 43,2 & 86,5 & 101,7 & 108,7 & 52,2 & 124,2 & 122,1 & 43,6 & 181,6 & 115,2 \\
\hline Ruse & 14,8 & 27,7 & 57,5 & 6,9 & 28,1 & 65,0 & 7,6 & 32,4 & 59,9 & 32,3 & 22,0 & 45,7 & 18,3 & 31,6 & 50,1 & 20,9 & 29,8 & 49,2 & 72,5 & \begin{tabular}{|c|}
94,7 \\
\end{tabular} & 114,1 & 37,6 & \begin{tabular}{|l|}
88,9 \\
\end{tabular} & 129,8 & 36,5 & 108,7 & 121,7 \\
\hline Silistra & 36,9 & 11,2 & 52,0 & 21,1 & 17,6 & 61,3 & 25,8 & 14,7 & 59,6 & 20,3 & 29,2 & 50,4 & 48,5 & 13,7 & 37,8 & 49,2 & $\mid 12,3$ & 38,4 & 89,2 & \begin{tabular}{|l|}
62,0 \\
\end{tabular} & 127,7 & 43,6 & 128,7 & 161,9 & 52,3 & 118,7 & 155,1 \\
\hline
\end{tabular}




\begin{tabular}{|c|c|c|c|c|c|c|c|c|c|c|c|c|c|c|c|c|c|c|c|c|c|}
\hline Northe & $, 7|18,8| 62,5$ & \begin{tabular}{l|l|l}
$, 62,0$ & 71,4
\end{tabular} & \begin{tabular}{|l|l|l|}
$7,82,89,4$ \\
\end{tabular} & 41,3 & 18,0 & 40,7 & 23,2 & 218,3 & 58,5 & 25,0 & 15,3 & $\mathbf{5 9 , 7}$ & 70,3 & 96,7 & 115,9 & 28,7 & $\mid 119,8$ & 122,0 & 31,0 & {$[148,8$} & \\
\hline Varna & \begin{tabular}{|l|l|l|}
8,7 & 23,6 & 67,6 \\
\end{tabular} & \begin{tabular}{|l|l|}
2,3 & $21,676,1$ \\
\end{tabular} & \begin{tabular}{|l|l|l|}
3,0 & 21,1 & 76,0 \\
\end{tabular} & 26,7 & 19,4 & 53,9 & 13,8 & 15,3 & 70,9 & 13,3 & 13,2 & 73,5 & 51,8 & $\mid 126,5$ & 105,0 & 16,8 & 141,3 & 107,3 & 22,2 & 159,7 & 103,4 \\
\hline Dobrich & \begin{tabular}{|l|l|l|}
3,9 & 10,8 & 55,3 \\
\end{tabular} & \begin{tabular}{|l|l|l|}
15,7 & 13,0 & 71,3 \\
\end{tabular} & $17,023,659,4$ & 16,9 & 18,7 & 64,4 & 33,9 & 19,6 & 46,5 & 40,5 & 14,5 & 44,9 & 90,1 & 60,1 & 124,4 & 46,4 & 66,2 & 153,3 & 41,9 & 162,5 & 32,2 \\
\hline Targovish & \begin{tabular}{|l|l|l|}
28,6 & $16,654,8$ \\
\end{tabular} & \begin{tabular}{|l|l|l|}
12,6 & 28,1 & 59,2 \\
\end{tabular} & $16,024,459,6$ & 37,6 & 17,9 & 44,4 & 35,6 & 21,1 & 43,3 & 35,1 & 19,9 & 45,0 & 83,1 & 74,0 & 127,0 & 35,5 & 133,1 & 136,9 & 45,6 & 122,4 & 32,6 \\
\hline Shumen & \begin{tabular}{|l|l|l|}
4,1 & 15,4 & 60,5 \\
\end{tabular} & \begin{tabular}{|l|l|l|}
11,4 & 28,1 & 60,5 \\
\end{tabular} & $13,4|28,5| 58,1$ & 34,4 & 22,5 & 43,1 & 29,7 & 723,6 & 46,7 & 36,3 & 19,6 & 44,1 & 72,3 & 74,0 & 131,9 & 38,4 & 119,3 & 129,4 & 37,0 & 145,3 & 31,8 \\
\hline Sout & $, 2|34,7| 49,1$ & \begin{tabular}{l|l|l|}
$6,69,5$ & 29,4 \\
\end{tabular} & \begin{tabular}{|l|l|l|l|}
6 & $\mathbf{6 5}, \mathbf{5 8 , 4}$ \\
\end{tabular} & 33,3 & 20,9 & 45,9 & 25,5 & 23,5 & 51,1 & 22,3 & 22,1 & 55,5 & 42,3 & {$[161,3$} & 122,3 & 25,7 & 125,2 & 125,5 & 27,5 & 160,3 & 105,1 \\
\hline Burgas & \begin{tabular}{|l|l|l|}
10,3 & $39,849,9$ \\
\end{tabular} & \begin{tabular}{|l|l|l|}
4,9 & 22,3 & 72,8 \\
\end{tabular} & \begin{tabular}{l|l|l|}
6,0 & 4,5 & 89,5 \\
\end{tabular} & 38,3 & 21,5 & 40,1 & 21,5 & 17,7 & 60,8 & 20,4 & 13,8 & 65,7 & 28,5 & 213,8 & 110,2 & 22,9 & 126,2 & 119,7 & 29,4 & 32,4 & 136,2 \\
\hline Sliven & \begin{tabular}{|l|l|l|}
33,3 & 11,2 & 55,5 \\
\end{tabular} & \begin{tabular}{|l|l|l|}
10,6 & 21,7 & 67,7 \\
\end{tabular} & $10,826,962,2$ & 36,1 & 18,6 & 45,3 & 29,6 & 21,7 & 48,7 & 27,9 & 21,7 & 50,4 & 55,9 & \begin{tabular}{|l|}
89,9 \\
\end{tabular} & 198,0 & 35,8 & 100,0 & 139,0 & 38,9 & 124,1 & 123,5 \\
\hline Stara_Zą & \begin{tabular}{|l|l|l|}
13,2 & $43,443,4$ \\
\end{tabular} & \begin{tabular}{|l|l|l|}
5,4 & 43,6 & 50,9 \\
\end{tabular} & $3,662,034,4$ & 59,5 & 12,5 & 28,0 & 20,0 & 33,5 & 46,5 & 18,8 & 32,6 & 48,6 & 50,6 & 133,0 & 105,2 & 27,2 & 130,2 & 109,5 & 19,0 & 190,2 & 70,9 \\
\hline Yambol & \begin{tabular}{|l|l|l|}
31,2 & 11,7 & 57,0 \\
\end{tabular} & \begin{tabular}{|l|l|l|}
13,6 & 17,4 & 69,0 \\
\end{tabular} & $13,432,753,8$ & 26,1 . & 32,6 & 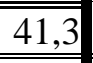 & 46,0 & 17,5 & 36,6 & 31,8 & 24,4 & 43,8 & 82,8 & 66,3 & 127,9 & 29,5 & 99,9 & 188,6 & 42,2 & 134,3 & 122,9 \\
\hline Sout & $5,3|20,6| 74,2$ & \begin{tabular}{l|l|l|l|}
2,0 & 16,2 \\
\end{tabular} & $1,6|14,7| 83,7$ & 37,7 & 17,7 & 44,6 & 7,7 & 718,8 & 73,5 & 7,2 & 15,5 & 77,4 & 58,2 & 88,8 & 109,4 & 25,6 & 89,8 & 110,4 & 22,5 & 94,8 & 108,2 \\
\hline Blagoevgrad & \begin{tabular}{|l|l|l|}
16,53 & 33,0 & 50,5 \\
\end{tabular} & \begin{tabular}{|l|l|l|}
11,8 & 29,6 & 58,6 \\
\end{tabular} & \begin{tabular}{l|l|l|}
12,0 & 28,2 & 59,8 \\
\end{tabular} & 18,6 & 23,3 & 58,1 & 23,4 & 33,6 & 43,1 & 24,2 & 29,0 & 46,8 & 78,2 & 89,7 & 120,0 & 50,4 & 88,4 & 136,0 & 49,6 & 97,3 & 127,7 \\
\hline Kyustendil & \begin{tabular}{|l|l|l|}
17,6 & 31,1 & 51,3 \\
\end{tabular} & \begin{tabular}{|l|l|l|}
14,2 & 30,7 & 55,1 \\
\end{tabular} & \begin{tabular}{|l|l|l|}
7,9 & 32,5 & 59,6 \\
\end{tabular} & 9,1 & 23,2 & 67,8 & 13,6 & 37,0 & 49,3 & 19,6 & 31,6 & 48,9 & 83,2 & 93,5 & 112,5 & 103,8 & 82,9 & 111,8 & 40,5 & 102,8 & 122,0 \\
\hline Pernik & \begin{tabular}{|l|l|l|}
20,0 & 19,8 & 60,2 \\
\end{tabular} & \begin{tabular}{|l|l|l|l|}
5,8 & 38,4 & 55,8 \\
\end{tabular} & \begin{tabular}{|l|l|l|}
7,1 & 27,2 & 65,7 \\
\end{tabular} & 21,1 . & 36,8 & 42,1 & 12,0 & 31,3 & 56,7 & 18,8 & 25,9 & 55,3 & 114,2 & 56,9 & 126,4 & 48,1 & 122,9 & 98,3 & 37,7 & 105,3 & 118,7 \\
\hline Sofia & \begin{tabular}{|l|l|l|}
14,2 & 38,4 & 47,3 \\
\end{tabular} & \begin{tabular}{l|l|l|}
6,0 & 52,5 & 41,5 \\
\end{tabular} & \begin{tabular}{|l|l|l|}
5,7 & 54,4 & 39,9 \\
\end{tabular} & 21,1 & 33,3 & 45,6 & 21,1 & 32,9 & 46,0 & 22,6 & 27,8 & 49,6 & 60,4 & 129,2 & 101,4 & 28,4 & 159,7 & 90,2 & 25,3 & 195,9 & 80,4 \\
\hline Sofia-city & \begin{tabular}{|l|l|l|}
0,8 & 15,8 & 83,4 \\
\end{tabular} & \begin{tabular}{l|l|l|}
0,2 & 11,5 & 88,3 \\
\end{tabular} & \begin{tabular}{l|l|l|}
0,2 & 9,6 & 90,2 \\
\end{tabular} & 17,5 & 34,9 & 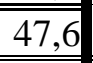 & 2,7 & 12,6 & 84,7 & 1,4 & 10,4 & 88,2 & 31,7 & \begin{tabular}{|l|}
90,4 \\
\end{tabular} & 104,3 & 9,1 & 91,0 & 104,2 & 16,2 & 91,7 & 102,3 \\
\hline South & $19,3 \mid 22,758,1$ & \begin{tabular}{ll|l|}
$9,29,7$ & 61,2 \\
\end{tabular} & \begin{tabular}{|l|l|l|}
8,2 & 29,9 & 61,9 \\
\end{tabular} & 23,6 & 29,7 & 46,7 & 25,2 & 26,2 & 48,5 & 27,7 & 24,7 & 47,6 & $\mathbf{5 9 , 4}$ & 96,4 & 131,7 & 36,3 & {$[113,1$} & 126,0 & 29,5 & 121,0 & 130,0 \\
\hline Kardzhali & \begin{tabular}{|l|l|l|}
27,0 & 18,7 & 54,4 \\
\end{tabular} & \begin{tabular}{|l|l|l|}
21,6 & 20,5 & 57,9 \\
\end{tabular} & \begin{tabular}{|l|l|l|}
17,7 & 22,7 & 59,6 \\
\end{tabular} & 2,6 & 17,5 & 79,9 & 30,3 & 26,7 & 43,0 & 49,2 & 18,4 & 32,5 & 105,5 & 72,2 & 112,0 & 71,4 & 76,8 & 134,5 & 36,0 & 123,7 & 183,5 \\
\hline Pazardzhik & \begin{tabular}{|l|l|l|}
21,6 & 23,5 & 54,8 \\
\end{tabular} & \begin{tabular}{|l|l|l|}
10,3 & 41,4 & 48,3 \\
\end{tabular} & $10,137,952,0$ & 32,4 & 23,5 & 44,11 & 30,2 & 27,6 & 42,3 & 37,4 & 23,1 & 39,5 & 42,2 & 128,8 & 180,0 & 34,2 & 150,3 & 114,2 & 27,1 & 164,1 & 131,6 \\
\hline Plovdiv & \begin{tabular}{|l|l|l|}
16,5 & $24,459,2$ \\
\end{tabular} & \begin{tabular}{|l|l|l|}
5,5 & 30,7 & 63,8 \\
\end{tabular} & \begin{tabular}{|l|l|l|}
4,8 & 30,8 & 64,4 \\
\end{tabular} & 25,5 & 25,9 & 48,5 & 20,5 & 27,4 & 52,2 & 18,8 & 27,4 & 53,8 & 72,5 & 90,2 & 117,7 & 26,9 & 112,1 & 122,3 & 25,2 & 112,6 & 119,8 \\
\hline Smolyan & \begin{tabular}{|l|l|l|}
18,6 & 15,0 & 66,4 \\
\end{tabular} & \begin{tabular}{|l|l|l|}
12,3 & 22,0 & 65,7 \\
\end{tabular} & \begin{tabular}{|l|l|l|}
12,3 & $30,657,1$ \\
\end{tabular} & |51,3 & 18,3 & 30,5 & 29,7 & 24,2 & 46,2 & 18,4 & 32,6 & 48,9 & 48,7 & 84,0 & 151,1 & 41,4 & 91,0 & 142,4 & 66,6 & 93,8 & 116,7 \\
\hline Haskovo & \begin{tabular}{|l|l|l|}
20,7 & 23,2 & 56,2 \\
\end{tabular} & \begin{tabular}{|l|l|l|}
11,3 & 20,9 & 67,8 \\
\end{tabular} & \begin{tabular}{|l|l|l|}
11,8 & 20,3 & 67,9 \\
\end{tabular} & 22,7 & 27,0 & $\begin{array}{l}50,3 \\
\end{array}$ & 29,0 & 22,5 & 48,5 & 32,6 & 19,1 & 48,4 & 67,2 & 95,2 & 125,1 & 39,0 & 93,0 & 139,8 & 36,3 & 106,3 & 140 \\
\hline
\end{tabular}


The relationship between the structure of industry and GDP per capita for the three years is low and statistically insignificant (2000 is 0.133 , for 2007 minus 0.05 , and for 2015 minus 0.129) but excluding six (Sofia-Capital, Sofia, Plovdiv, Stara Zagora, Bourgas and Varna), which are highly urbanized, with a lower share of the employed and a high share of the services, a significant correlation coefficient of 0,466 for 2000, 0,778 for 2007 and 0,497 for 2015. In 2007, compared to 2000, this coefficient grew and then declined in 2015. It turns out that the share of the employed in the industrial sector is a determining factor for the development of the districts (with the exception of the urban centers). Unlike other areas, urbanized centers have reached a certain level of industrialization and continue to increase their efficiency by increasing the relative share of services as a sector allowing economic growth and increasing competitiveness. Thus, they have a higher economic development potential compared to other areas, and better opportunities for the development of urbanized centers create opportunities for increasing regional disparities.

The dependency between the share of employees in the services sector and GDP per capita has a correlation coefficient that is statistically significant for all years surveyed in 2000 it was 0.624 , in 2007 it was 0.811 and in 2015 it was 0.745 . In 2000, this coefficient shows a significant dependence between the variables. Its importance has grown over time and in 2007 and 2015 there is already a strong correlation between the employed in this sector and GDP per person.

The statistical analysis, as a whole, shows that the higher share of the employed in the agrarian sector is indicative of lower labor productivity and the restructuring of labor force to sectors with higher labor productivity is a significant factor for raising the GDP per capita of the population. The establishment of a more favorable structure of the employed in the region, consisting in the overflowing of labor-intensive sectors into less labor intensive, is a prerequisite for its economic development. The decline in the number of employed in agriculture implies the creation of a more favorable structure resulting in higher overall labor productivity and GDP per person.

\section{CONCLUSIONS}

The analysis identifies the Southeast and Southwest regions as well as the constituent areas with a better development perspective due to the relatively more favorable economic and demographic indicators. However, the North-West region has a high share of employed and GVA in the agrarian sector and a low degree of industrialization. This defines it as the region with the most inefficient structure and the lowest potential for economic growth.

A potential for development in terms of labor productivity is in the services sector. The relative productivity of labor is significantly higher than in other sectors, and this gives reason to define it as a sector with favorable opportunities for change. The relationship and the closeness of dependence between the employed in this sector and the GDP per capita is confirmed by a high positive correlation coefficient, which makes it a good indicator of the magnitude of GDP by individual areas. It is found that there are no significant differences in the structure of the individual sectors in 2015 compared to 2007 as opposed to the structure of these two years compared to 2000. This could mean that the changes in 2007 have determined the direction of development and have defined the relative importance of the economic sectors.

To summarize, in order to "improve" the industrial structure of a country or region, the necessary prerequisites for such "improvement" should be created above all, in terms of the efficiency of physical and human capital. For example, this can happen as developing regions improve the efficiency of physical and human capital in higher efficiency activities, of course, this is in line with their capabilities - their level of economic development and their comparative advantages. It can then be expected that structural changes will be as effective as possible (3).

\section{REFERENCES}

1. Kuznets, S. 1971. Economic Growth of Nations: Total Output and Production Structure, Cambridge, MA, Harvard University Press, p. 348

2. Pasinetti, L. 1981. Structural Change and Economic Growth. A Theoretical Essay on the Dynamics of the Wealth of Nations, Cambridge University Press, Cambridge.

3. Justin Yifu Lin Economic Development And Structural Change, Senior Vice President and Chief Economist The World Ban, Lecture at Cairo University Cairo, Egypt November 5, 2009 